\title{
房屋建筑土木工程施工中的注浆技术分析
}

\author{
孟海昆 \\ 重庆高新鼎诚置业有限公司，重庆 400080
}

[摘要]从当前房屋建筑土木工程的现状来看, 注浆技术的应用是较为普遍的, 通过其可以使得施工速度明显加快, 质量也能 够切实提升。在现阶段，注浆工艺更为成熟，能够将传统工艺中存在的缺陷予以消除，进而使得建筑质量达到标准要求。在 科技发展速度持续加快之际, 设备的先进性也明显提成, 这就使得注浆技术更为完善。高分子材料得到应用后, 计算机的自 动化程度也提高了很多, 确保注浆技术能够得到充分利用, 可以使得建筑工程更加稳定, 施工质量也能够达到标准要求。 [关键词]房屋建筑; 土木工程; 注浆技术; 施工; 分析

DOI: $10.33142 /$ ec.v3i9.2526

中图分类号: TU74

文献标识码：A

\section{Analysis of Grouting Technology in Building Civil Engineering Construction}

\author{
MENG Haikun
}

Chongqing Hi-tech Dingcheng Real Estate Co., Ltd., Chongqing, 400080, China

\begin{abstract}
From the current situation of building civil engineering, the application of grouting technology is more common, through which the construction speed can be significantly accelerated and the quality can be effectively improved. At this stage, the grouting technology is more mature, which can eliminate the defects existing in the traditional technology, and then make the construction quality meet the standard requirements. With the continuous development of science and technology, the advanced nature of equipment has also been improved significantly, which makes the grouting technology more perfect. After the application of polymer materials, the degree of computer automation is also improved a lot, to ensure that the grouting technology can be fully used, can make the construction project more stable, the construction quality can also meet the standard requirements.
\end{abstract}

Keywords: housing construction; civil engineering; grouting technology; construction; analysis

\section{引言}

在展开建筑施工时, 采用的施工技术会对工程质量产生直接的影响。施工中所要采用的施工技术是较多的, 而注 浆技术则属于关键技术, 简单来说就是通过压送方式使得浆液能够进入到土层、岩石层中, 这样在凝固之后就可获得 颗粒, 进而对分析进行有效填充。对注浆技术予以分析可知, 其适应性是较强的, 应用范围也是较为广泛的。对房屋 进行建设、修缮的过程中, 注浆技术的应用是较为普遍的, 通过此种技术可以使得房屋发生渗漏的几率大幅降低, 具 有的防水性能切实增强。当然, 施工人员也必要对细节予以重点关注, 选择合适的措施来保证施工质量大幅提升。

\section{1 注浆技术概述及其特点}

1.1 注浆技术

利用压送设备来使得浆液能够顺利进入到地层裂缝、孔洞中, 在冷凝之后就可以对层岩进行加固处理, 如此一来, 房屋建筑的安全就能够得到保证, 质量也可大幅提高。注浆技术具有的优势是较为明显的, 其对周边环境不会造成破 坏, 工艺也并不复杂, 而且投入的成本相对较低。展开土木工程施工的过程中, 必须要将注浆技术予以充分应用, 这 样可以使得牢固性大幅提高。在对浆液进行选择的过程中, 气候、湿度以及地质条件等是必须要予以考虑的, 如此可 以使得浆液材料是最为适合的。这里需要指出的是, 浆液材料的刚性应该较强, 并具有良好的黏结力度, 尤其要保证 干凝质量达到标准要求 ${ }^{[1]}$ 。另外来说, 为了保证注浆效果更为理想, 可以将两种及以上材料进行混合应用。比方说, 将 水泥、水予以混合之后能够使得黏结粒有明显的提升, 如果再掺入适合的辅助材料则可使得效果更为理想。对于施工 技术人员而言，必须要对各种影响因素予以重点关注，保证选用的注浆材料是最为适宜的。

\section{2 特点}

(1)工艺并不复杂, 具有一定的灵活性, 可以很好的适应施工环境。注浆的过程中, 操作是较为简单的, 即使要对 某些部位进行拆除, 施工也不会受到影响。(2)占地面积不大, 而且能够保证加固效果达到预期, 展开小范围修补工作 
时, 周边存在的一些物品也不会带来较大影响。(3)防水性能较强, 在建筑施工时对其予以充分应用可以使得硂具有的 防水性能大幅提升。(4)在可以起到良好的补充作用, 其力学性能是相对较高的, 而且能够有效抵御腐蚀, 使用过程中 对周边环境产生的破坏较小, 环保性能是较为显著的。注浆技术主要是利用液压方式使得固体材料变为黏接剂, 这样 就可使得黏结效果更为理想, 同时可以避免钢筋材料受到破坏。(5)对注浆技术加以利用能够使得砤具有的性能大幅提 高, 使用寿命也能够有一定程度延长, 即使硂出现了腐朽的情况, 通过此项技术也可使得硂结构发生变化, 促使其性 能提高 ${ }^{[2]}$ 。

\section{2 注浆技术的分类}

（1）静压注浆。施工前要完成好分析工作，了解施工现场的现状，在此基础上将施工措施予以确定。地基土层较 软的话, 可以选择䢃裂注浆法, 对泥浆比重、压力较大的优势加以利用, 确保其可以在地基内部实现有序延伸, 在凝 固后就可使得缝隙填充目的达成，地基强度自然就可得到提高。

（2）高压喷射注浆。在当下的房建、水利等工作中，高压喷射注浆技术的使用是较为普遍的，通过其可以使得土 层加固效果更为理想, 具有的承载力大幅提升。另外来说, 通过此项技术还能够实现防水目标, 当然, 要依据现场状 况来合理运用注浆技术。

（3）裂注浆结合。在进行注浆操作时，通过高压喷射技术获得泥浆柱体，继而采用静压注浆技术来使得泥浆能够 均匀分布在地基周边，这样一来，泥浆凝固后就能够变成骨架，使得地基保护目标切实达成。一般来说，细沙土层、 粉土土层的处理可以采用此种技术，处理效果也是较为理想的。 ${ }^{[3]}$ 。

\section{3 注浆技术存在于土木工程施工建筑中}

\section{1 土木工程中所运用到的注浆技术}

在展开土木工程施工时, 通过注浆技术能够保证土层的适用性大幅高, 而在实际应用时必须要保证相关的操作更 具专业性。打孔选用专门的工具, 两孔间距控制在 $300 \mathrm{~mm}$, 并要在重点特定位置进行打孔, 并要做好密封处理, 确保浆 体不会发生泄漏, 在此之后方可对管子进行埋入, 继而对浆体予以注入, 在此过程中, 裂纹温度、干燥程度等必须要 适时关注。浆体过于干燥的话, 则要掺入适量的水。在完成注浆工作后, 要确保静置时间达到 $14 \mathrm{~h}$, 如此方可保证混凝 土的凝固效果达到预期。在这段时间内, 应该指定专门人员进行保护, 因为在空气中含有一定量的酸碱性物质, 其对 施工质量造成的影响是较大的, 所以要选择合适的措施进行保护 ${ }^{[4]}$ 。

\section{2 厨房卫可运用到的注浆技术}

从房建施工的现状来看, 厨房、卫生间是需要重点关注的地方, 因而在这里集聚的水是较多的, 一旦建筑结构存 在密封不到位的情况, 泄漏、破裂等也就会出现。因而在展开室内装修时可以对注浆技术加以应用, 也就选择环氧化 物溶液在进行填充处理, 这样可以使得密封性大幅提高, 确保防渗目标切实达成。另外可选用喷油技术来予以处理, 此种技术的操作非常简便，而且不会对房间的美观性产生影响，因而其应用是较为常见的 ${ }^{[5]}$ 。

\section{3 防渗漏的运用}

若想使得房屋具有的防潮性能、抗渗能力切实提升, 则要保证选用的材料是最为合适的, 并将注浆方法的作用充 分发挥出来。切实做好注浆处理可以使得地基更为稳定, 而且地下水产生的影响也可控制在较小的范围内, 如此就可 保证建筑质量达到标准要求。另外来说, 在展开空间建设时要对地下室、车库的施工予以重点关注, 通过注浆技术来 保证地下空间中存在的渗透点得到有效处理，确保整个空间的湿度不会出现过高的状况。

\section{4 对墙体和门的修理}

在整个建筑物中, 门窗、墙体发生损坏的几率是较高的, 导致此种情况出现的原因是较多的, 常见的是使用的材 料存在质量问题, 采用的施工方法不合适, 维护没有做到位等。对墙体进行修补时, 浇注工艺的使用能够提高实际效 果。混凝土颗粒通常是较为粗䊁的, 在使用一段时间后, 墙面必然会出现裂缝, 这是因为受到温度的影响, 墙体材料 出现膨胀, 而程度不一, 进而导致裂缝产生。在对此种缺陷进行修补时, 注浆技术是较为合适的。外墙面的装饰已经 完成后, 高压喷射浆技术就无法使用, 此时对墙体进行修补则要选择埋管灌注技术, 这样可以使得修补效果达到预期, 墙体具有的稳定性能够大幅提升。另外来说, 建筑物的门窗出现裂㖓的概率也是较大的, 这是因为在对门窗进行安装 的过程中选择的材料未达标准, 或是镶嵌方法不够合理。已经安装完成的门窗进行更换会带来较大的经济损失, 因而 在对门窗裂缝进行处理时可以选择注浆技术, 除了能够保证处理效果, 而且经济性也是较高的。墙壁裂缝多是以门窗 
为中心, 呈现出向外扩展的状态, 通过埋管注浆技术则能够有效完成裂缝处理工作, 并可以保证墙体更为稳定, 门窗 安装自然也就不会受到影响 ${ }^{[6]}$ 。

\section{5 注浆技术在混凝土浇筑结构中的运用}

从建筑构件的加工来看, 混凝土技术的应用是不可忽视的, 尤其要寻找到存在缺陷之处。在对混凝土加工技术予 以应用时, 先要完成好打孔工作, 孔间距一般应控制在 300 至 $400 \mathrm{~mm}$ 间, 同时要保证间隙直径能够处于 0.5 至 $1.2 \mathrm{~mm}$ 间。如果裂缝过于潮湿的话, 则要对采用特殊方法进行处理。湿裂缝的处理过程中, 孔间距应该保持 25 至 $40 \mathrm{~mm}$ 间, 使用环氧胶机械能密封处理, 如此可以使得液体渗漏得到有效控制。埋设的水泥管道应该要适宜, 而且注浆材料中可 以掺入一定量的水, 如此可以使得加固的整体效果更为理想。当然, 环境较为干燥的话, 选用的材料则要保证其粘度 不能过高, 而且要在确定的时间内完成处理工作, 如此可以使得加固的效果达到预期。

\section{6 地下室部分注浆技术应用要点}

从建筑工程的整体结构来看, 地下室结构是关键所在, 其对工程质量、安全能够产生直接影响, 使用性能也与其 直接相关。所以说, 正式施工前应该要完成实地调研工作, 地质、地形等方面的因素均要有切实的了解, 将不同因素 可能带来的影响寻找出来。在获得相关数据后展开施工图纸的设计工作, 如此方可使得图纸设计更为合理。另外, 还 要指定专业人员来对勘察报告进行分析, 依据相关的数据来展开问题评估工作, 将每个施工环节中可能出现的问题寻 找出来, 并进行实验验证, 进而确定施工顺序。钻孔、注浆也是不可忽视的, 依据使用的材料来对钻孔规格予以明确, 角度应该保持为 45 度。首次注浆应该要对压力缓慢上调, 达到 $2.0 \mathrm{mpa}$ 方可停止, 如此科颜氏的浆液的流动不受影响。 除此以外, 施工现场中设置的排水通道必须要是合理的, 确保周边建筑不会受到影响, 并能够对生态环境起到保护作 用。为了使得施工质量达到要求, 要将防范措施切实做到位, 所有的施工环节均要和相关的要求相符。

\section{4 结束语}

综上所述, 注浆技术在现代房屋建筑中得到了广泛应用。在修补房屋建筑裂缝问题方面, 注浆技术发挥着积极作 用。与其他技术相比, 注浆技术具有工艺简单、适应性强、加固效果好等显著优势。注浆技术主要有静压注浆法、䢃 裂灌浆法、高压喷射注浆法以及复合注浆法等, 在选择过程中应该根据项目的特点合理选择。注浆技术的应用不仅改 善可修补效果，而且提高了房屋建筑的综合性能，既保证建筑物的美观，又提高了其实用性。

\section{[参考文献]}

[1]刘君.房屋建筑土木工程施工中的注浆技术分析 [J].门窗, 2019(10): 73-74.

[2]白龙龙.房屋建筑土木工程施工中的注浆技术分析 [J]. 建材与装饰, 2020(03): 7-8.

[3]王威.房屋建筑土木工程施工中的注浆技术分析 [J].建材与装饰, 2020(07): 35-36.

[4] 党立涛. 注浆技术在建筑土木工程施工中的应用标准探究 [J].中国多媒体与网络教学学报(上旬 刊), 2020 (01): 212-213.

[5]魏杰. 房屋建筑工程施工中注浆技术分析 [J]. 建筑技术开发, 2020, $47(02): 48-49$.

[6]王瀚斌.浅谈房屋建筑土木工程施工中的注浆技术分析 [J]. 江西建材, 2017 (13): 81-87.

作者简介: 孟海昆 (1981.6-), 男, 重庆大学, 大学本科, 所学专业: 土木工程, 职务: 工程部经理, 所在职务的年 限: 7 年, 高级工程师。 